\title{
Selectrodialysis and ion-exchange resins as integration processes for copper and zinc recovery from metallurgical streams containing arsenic
}

\author{
M. Reig ${ }^{1}$, X. Vecino ${ }^{1}$, M. Hermassi ${ }^{1}$, J. López ${ }^{1}$, C. Valderrama ${ }^{1}$, O. Gibert ${ }^{1}$, J.L. Cortina ${ }^{1,2}$ \\ ${ }^{1}$ Chemical Engineering Department, UPC-Barcelona TECH; Barcelona Research Center for Multiscale Science and Engineering, C/ Eduard \\ Maristany 10-14, Campus Diagonal-Besòs, 08930 Barcelona, Spain. \\ ${ }^{2}$ CETaqua, Carretera d'Esplugues, 75, 08940 Cornellà de Llobregat, Spain.
}

Highlights: SED is an innovative technology for metallurgical effluents treatment; IEX resin is an efficient methodology for metal separation and concentration steps; CU and $\mathrm{Zn}$ were recovered by means of integration processes (SED and IEX resins)

Keywords: selectrodialysis; ion-exchange process; metal recovery; free-arsenic stream; metallurgical industry; circular economy.

\section{Introduction}

Nowadays, the shortage of water and the need to reduce the associated environmental impacts make it necessary not only to treat it but also to reuse the wastewater. In addition, all industrial sectors generate waste effluents with great potential to be valorized. The metallurgical sector is an industry that produces acid currents that contain heavy metals (e.g. copper (Cu), zinc (Zn)) and impurities (e.g. arsenic (As)). Heavy metals have an added value, which could be obtained by the metalllurgical waste-stream treatment.

In this study, a circular economy scheme is proposed in order to be able to take advantage of an acidic effluent produced in the copper and zinc metallurgiical industries. From this point of view, two ion-exchange (IEX) technologies were used to separate and concentrate its main elements ( $\mathrm{Cu}, \mathrm{Zn}$ and $\mathrm{As}$ ): (i) selectrodialysis (SED) following by (ii) IEX resins. Figure 1 shows the flowchart of integrated processes (SED and IEX resins) for copper and zinc recovery and arsenic removal from acidic metallurgical streams.

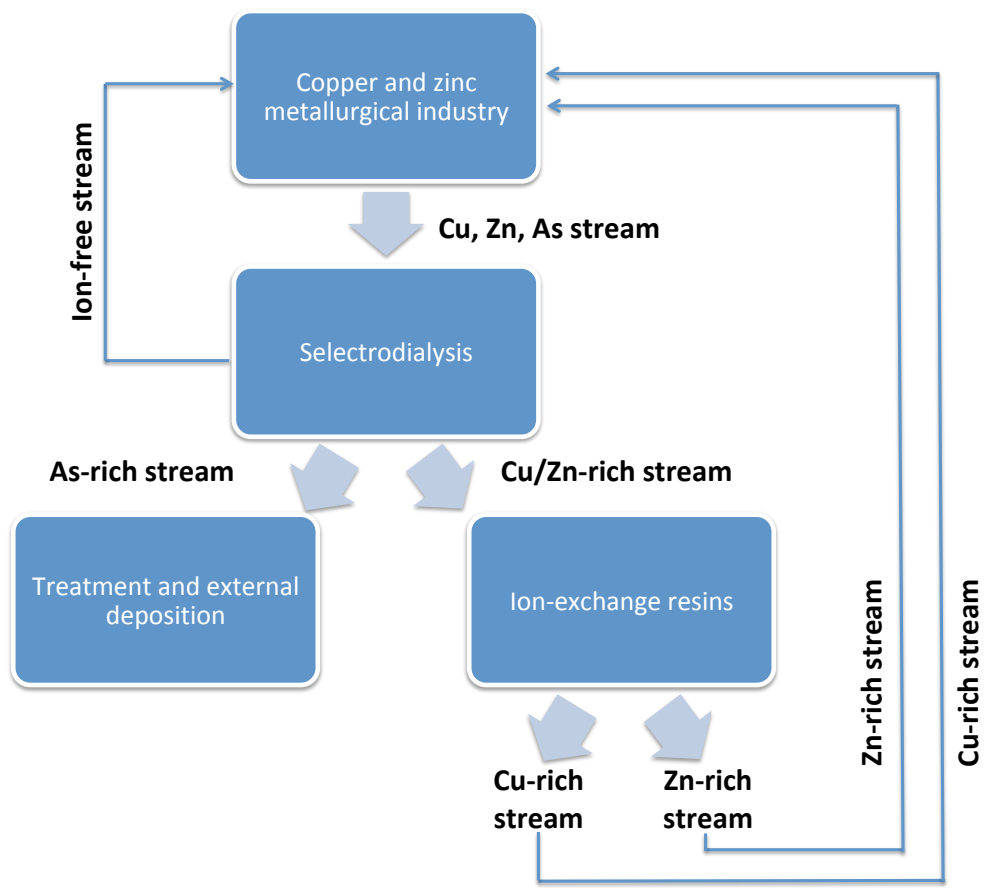

Figure 1. Circular economy scheme purposed for copper and zinc recovery and arsenic removal in the metallurgical industry. 
By means of a novel electrodialysis-based technology, named SED, is possible to separate different charged ions when electrical current is applied, using standard and mono-selective membranes (Zhang et al. 2012; Reig et al. 2018). In this study, SED was used to separate As from Cu and Zn. Afterwards, the obtained As-rich stream could be treated properly for external disposal, taking into account the arsenic toxicity. Besides, after the SED process, a $\mathrm{Cu} / \mathrm{Zn}$-rich stream was also obtained. Sequently, two ion-exchange resins were used to separate both ions ( $\mathrm{Cu}$ and $\mathrm{Zn}$ ) in order to reuse both streams in the cooper and zinc metallurgical industries, respectively (Juang et al. 1992).

\section{Material and Methods}

An ED lab-scale set-up (ED 64-4) supplied by PCCell (Germany) was employed to conduct the SED experiments. Fujifilm Manufacturing Europe B.V (Netherlands) membranes (standard anionic, standard cationic and monovalent selective cation-exchange) were placed between two electrodes and constant voltage of $7 \mathrm{~V}$ was applied. An acidic metallurgical stream containing $170 \mathrm{mM} \mathrm{Cu}(\mathrm{II}), 70 \mathrm{mM} \mathrm{Zn(II)}$ and $110 \mathrm{mM} \mathrm{As}(\mathrm{V})$ was treated in order to be able to separate the As from $\mathrm{Cu}$ and $\mathrm{Zn}$. Initial solution in the $\mathrm{Cu} / \mathrm{Zn}$-rich compartment was $300 \mathrm{mM} \mathrm{H}_{2} \mathrm{SO}_{4}$; whereas initial solutions in the As-rich compartment and electrode rinse streams were $100 \mathrm{mM} \mathrm{Na}_{2} \mathrm{SO}_{4}$. Samples collected during the experiments were analysed by inductively coupled plasma (ICP) to determine $\mathrm{Cu}, \mathrm{Zn}$ and As concentrations in each stream along the time.

Once an As-free stream was obtained, the $\mathrm{Cu} / \mathrm{Zn}$-rich stream was treated by IEX resins in a fixed-bed configuration (1.1 cm internal diameter and $7.5 \mathrm{~cm}$ height), using $2.75 \mathrm{~g}$ of resin at $1.95 \mathrm{~mL} / \mathrm{min}$ of flow rate, in order to separate $\mathrm{Cu}$ from Zn. Two different IEX resins were used: Purolite S960 (chelating resin) and Lewatit OC VP 1026 (solventimpregnated resin), for testing which resin has the highest separation factor of both cations ( $\mathrm{Cu}$ and $\mathrm{Zn}$ ).

\section{Results and Discussion}

SED experiments were stopped when the feed solution conductivity was reaching a value around zero. For this reason, conductivity was monitored in each stream during the trials. The electrode rinse stream has no interactions with the other operational streams, so its conductivity remains constant during the tests. As exhibited in Figure 2, As concentration increased in the As-rich stream, while $\mathrm{Cu}$ and $\mathrm{Zn}$ concentrations increased in the $\mathrm{Cu} / \mathrm{Zn}$-rich stream one. Overall, SED process allowed to recover $49.1 \%$ of As (for its subsequent treatment and disposal) and $81.9 \%$ of $\mathrm{Cu} / \mathrm{Zn}$. The energy consumption of the SED process was about $4.8 \mathrm{kWh} / \mathrm{kg} \mathrm{Cu+Zn}$ produced.

a)

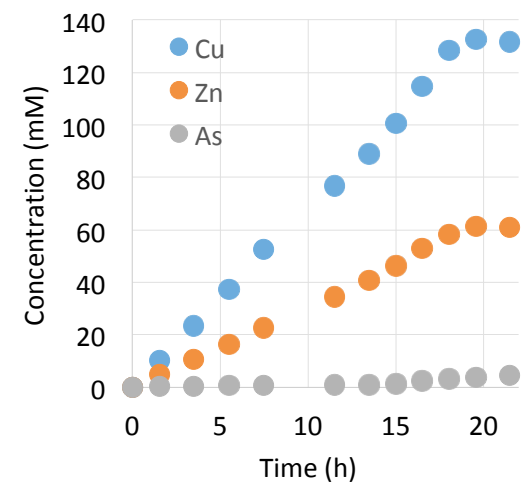

b)

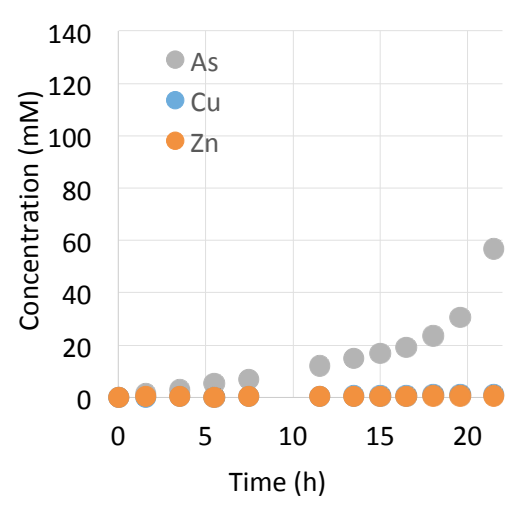

Figure 2. SED results a) in the $\mathrm{Cu} / \mathrm{Zn}$-rich stream and b) in the As-rich stream over time

Afterwards, IEX resins were used to treat the $\mathrm{Cu} / \mathrm{Zn}$-rich stream in a fixed-bed column set-up. Best $\mathrm{Cu}$ and $\mathrm{Zn}$ separation factors were obtained using the Lewatit 1026 resin. In this case, the acidic metallurgical stream (at $\mathrm{pH}$ 2.7) was treated by the IEX solvent-impregnated resin followed by an elution step using $\mathrm{H}_{2} \mathrm{SO}_{4} 1 \mathrm{M}$, which allowed to recover $69 \%$ of $\mathrm{Zn}$ (Figure 3a). Then, the $\mathrm{pH}$ was increased up to 4.7 to exchange $\mathrm{Cu}$ ions (elution step was also conducted using $\mathrm{H}_{2} \mathrm{SO}_{4} 1 \mathrm{M}$ ) achieving $97 \%$ of Cu recovery (Figure $3 \mathrm{~b}$ ). 
a)

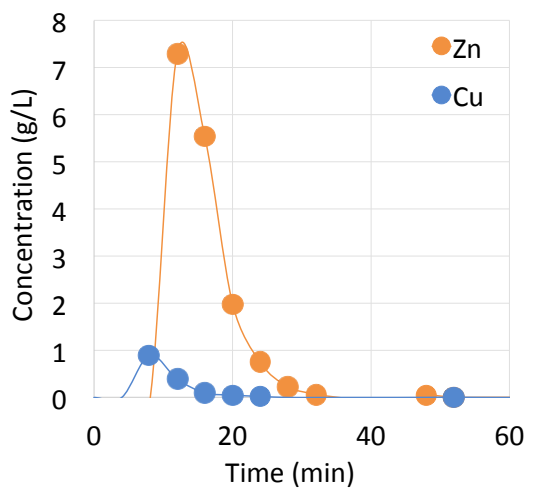

b)

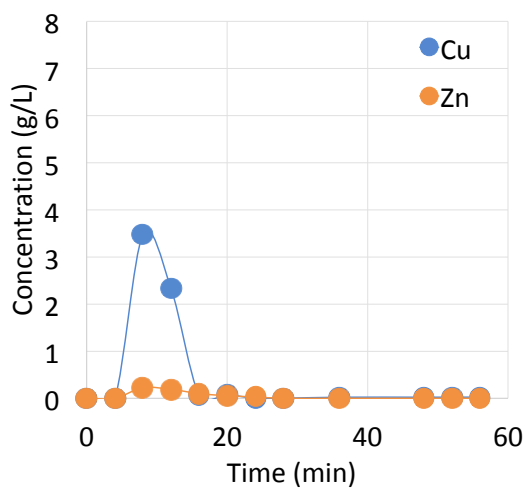

Figure 3. IEX elution curves by Lewatit 1026 resin for a) $\mathrm{Zn}$ and b) Cu recuperation, respectively.

\section{Conclusion}

To summarize, it was possible to separate As from an acidic metallurgical stream containing mainly $\mathrm{As}, \mathrm{Cu}$ and $\mathrm{Zn}$ by SED technology and also it was possible to separate and concentrate $\mathrm{Cu}$ and $\mathrm{Zn}$ streams by IEX resins. Furthermore, copper and zinc streams can be reused in the copper and zinc metallurgical industries, respectively; promoting in this way the circular economy in the metallurgical sector.

\section{References}

Juang R.S. and Su J.Y., Separation of zinc and copper from aqueous sulfate solutions using bis(2ethylhexyl)phosphoric acid-impregnated macroporous resin, Ind. Eng. Chem. Res. 31 (12) (1992) 2779-2783.

Reig M., Vecino X., Valderrama C., Gibert O., Cortina J.L., Application of selectrodialysis for the removal of As from metallurgical process waters: Recovery of Cu and Zn, Sep. Purif. Technol. 195 (2018) 404-412.

Zhang Y., Paepen S., Pinoy L., Meesschaert B., Van der Bruggen B., Selectrodialysis: Fractionation of divalent ions from monovalent ions in a novel electrodialysis stack, Sep. Purif. Technol. 88 (2012) 191-201.

\section{Acknowledgments}

This research was supported by the Waste2Product project (CTM2014-57302-R) and by R2MIT project (CTM2017$85346-R$ ) financed by the Spanish Ministry of Economy and Competitiveness (MINECO) and the Catalan Government (ref. 2017-SGR-312), Spain. As well, Xanel Vecino thanks MINECO for her Juan de la Cierva contract (ref. IJCl-2016-27445) and Julio López for his pre-doctoral grant (ref. BES-2015-075051). 